\title{
Rituais pós-modernos de consumo: 0 reencantamento presente numa pena perpétua
} Postmodern rituals of consumption: The re-enchantment present in a life sentence

Karla Patriota Bronsztein ${ }^{1}$

Bruno Anselmo da Silva

Resumo Relacionamos neste artigo as práticas de consumo atuais com a noção de reencantamento do mundo, como postulado na leitura feita por Pierucci, do conceito de mundo desencantado de Max Weber. Tomamos como base para tal aproximação o processo assinalado por Maffesoli e Bougnoux, de revalorização do sentimento e dos contatos mais primitivos nas relações sociais pós-modernas $e$ as análises de Bauman sobre a "sociedade de consumidores". A leitura acerca da lógica ritual que perpassa tanto consumo quanto magia revela-se desafiadora e, ao mesmo tempo, bastante profícua para que se observe a emergência de um possivel reencantamento do mundo via consumo.

Palavras-chave: Consumo; Pós-modernidade; Reencantamento; Identidade

Abstract In this article, we relate the current consumption practices with the notion of re-enchantment of the world, as postulated in Pierucci's reading from the Max Weber's concept of disenchantment world. We take as base for this approach the process marked by Maffesoli and Bougnoux, of revaluation of the feeling and the most primitive contacts in the post modern social relations, and Bauman's analyzes about the "society of consumers". The reading regarding the

\footnotetext{
${ }^{1}$ Universidade Federal de Pernambuco - UFPE, Recife, PE, Brasil.

E-mail: k.patriota@gmail.com

2 Universidade Federal de Pernambuco - UFPE, Recife, PE, Brasil.

E-mail: brunoanselmo.br@gmail.com
} 
ritual logic that surpasses, both consumption and magic, proves to be challenging and at the same time very effective to observe the emergency of a possible re-enchantment of the world via consumption.

Keywords: Consumption; Postmodernity; Re-enchantment; Identity 
Ousadia e humildade. Amor e justiça. Liberdade e limite. Realidades aparentemente opostas, via de regra, são difíceis de conjugar. Difícil determinar o fio que gera unidade, a lógica que perpassa, que dá sentido. Para além das aparências, entretanto, ao escaparmos das distrações do senso comum, determinados objetos surpreendem ao revelarem as complexas nuances e as interligações que os constituem. Isso se mostra especialmente verdadeiro ao tentarmos entender os hábitos de consumo no cotidiano pós-moderno.

Tendo tal complexidade como alicerce estrutural, neste artigo nos lançamos ao desafio de olhar para as práticas de consumo atuais, a partir da aproximação entre duas ideias à primeira vista contraditórias: a primeira delas de semântica bem positiva e, até pode-se dizer, "alegre"; a outra ideia mais crítica, tida por alguns como demasiado pessimista. Estamos nos referindo à noção de "reencantamento do mundo", releitura do que foi postulado por Max Weber quando discorreu sobre a emergência de um mundo desencantado, reflexões que serão ancoradas em autores contemporâneos como Michel Maffesoli, Colin Campbell, Antônio Flávio Pierucci e Déborah Pereira.

Em segundo lugar, recorreremos às análises de viés crítico acerca da chamada "sociedade de consumidores" propostas pelo sociólogo polonês Zygmunt Bauman. Entendemos que analisar o consumo na pós-modernidade requer certa reflexão sobre encantamento e aprisionamento. Impossível conjugar? Improvável, talvez.

Comecemos pela alegria. Como bem observou Antônio Flávio Pierucci, em seu esforço exegético para compreender a mais exata acepção do conceito de "desencantamento do mundo" no conjunto da obra de Max Weber, "em qualquer língua do mundo a ideia de encantamento se diz gostosamente, gozosamente, em formas belas, arrebatadoras, fascinantes" (PIERUCCI, 2005, p. 31). A plasticidade desta palavra, que evoca belas imagens e significações poéticas, somada a outros fatores como falhas no processo de tradução do termo para a língua portuguesa, além de sugerir interpretações da ordem do senso comum, tem, por isso mesmo, dificultado o entendimento do conceito formulado por Weber. Como Pierucci demonstra no referido trabalho, para Max 
Weber desencantamento do mundo não tem a ver com melancolia, desesperança ou - quando traduzido em português por desencanto - “um estado mental de desilusão pessoal com o mundo (moderno) ou com os rumos da sociedade" (PIERUCCI, 2005, p. 34).

Mas afinal, qual o significado que Max Weber atribuiu ao conceito de desencantamento do mundo? Como não podia deixar de ser, este é um questionamento basilar para compreendermos a possibilidade de retorno do encantamento que estaria em curso na atualidade. Pierucci destaca que o desencantamento do mundo em Weber possui dois significados bastante precisos, a saber: 1) o desencantamento do mundo pela religião (através do processo histórico e gradual de desprezo da magia como meio de salvação e de normatização moral radical da vida religiosa), que remonta ao profetismo judaico ${ }^{3}$ e encontra sua expressão máxima no protestantismo ascético ${ }^{4}$ do puritanismo que, em muitos momentos, passou a tratar profissão como sinônimo para vocação, no que se poderia chamar de "distorção protestante" (GUINNESS, 2001, p. 102); e 2) o desencantamento do mundo pela racionalidade da ciência. Os dois sentidos são concomitantes na obra de Weber, embora o primeiro tenha a primazia sobre o segundo:

Em Weber o significado literal de desencantamento do mundo como desmagificação da busca da salvação talvez seja mesmo seu sentido mais forte e decisivo, na medida em que nada mais é que a outra face do processo de moralização da prática religiosa, um processo histórico-religioso tipicamente ocidental e de sérias consequências para o viver humano (PIERUCCI, 2005, p. 146).

Na estrada que conduziu à modernidade, a racionalização prático-técnica (científica) teria pegado carona na racionalização prático-ética (religiosa), no processo que Weber denominou de desencantamento do mundo. O abandono da crença religiosa, como forma válida de explicar

\footnotetext{
3 Em seus argumentos contrários à idolatria e ao culto a outros deuses, considerados falsos pela concepção monoteísta judaica.

4 Principalmente a partir da retirada da importância dada, pelo catolicismo romano, aos sacramentos como "meios visíveis" para o alcance da Graça invisível de Deus. Com isso, perde-se ainda mais um pouco da magia litúrgico-religiosa.
} 
a realidade, certamente tirou do mundo o encanto que lhe conferia plausibilidade. Porém, antes disso, um processo de racionalização dentro da própria vida religiosa é o que de fato começou a conduzir o Ocidente à modernidade. O próprio racionalismo do protestantismo, como postulado por Weber (1963, p. 248), já demarcava a emergência do "domínio racional do mundo" na perspectiva do modelo ocidental de racionalização, com seus amplos e fundamentais processos sociais e culturais, mas principalmente pelo imbricamento entre o "desencanto e a intelectualização do mundo” (BRUBAKER, 1996, p. 642).

Assim, é correto pensar que a noção de desencantamento do mundo ajuda a entendermos a modernidade. Para Weber, porém, curiosamente (ou não!), a compreensão do Ocidente tem como ponto de partida essa faceta da cultura chamada experiência com o sagrado ou, simplesmente, religião. O sociólogo alemão demonstra, categoricamente, o papel determinante da religião para que se analisem os comportamentos humanos em sociedade: "as forças mágicas e religiosas e as ideias éticas de dever nelas baseadas têm estado sempre, no passado, entre as mais importantes influências formativas de conduta" (WEBER, 2004, p. 32). Por conseguinte, percebe-se que ainda que a religião não seja a única fonte capaz de fornecer respostas para a análise social, sem dúvida, ela tem muito a contribuir. É, portanto, essencial ter isso em mente ao nos referirmos a um suposto "reencantamento do mundo", processo este que estaríamos vivenciando na passagem da modernidade para a pós-modernidade e que, no presente artigo, é o que, de fato, nos interessa.

Antes de tudo, é ainda necessário, para os nossos objetivos de reflexão, esclarecer que Weber distinguiu duas formas de relação com o sagrado: a magia e a religião propriamente dita. A magia diz respeito a um estágio mais primitivo de religiosidade, de cunho animista, no qual seria possível manipular os deuses e os espíritos que povoam cada parte do mundo - estes nem bons nem maus em sua essência - para atingir determinados interesses. Já a religião, para o autor, estágio posterior à magia, está necessariamente ligada a um padrão doutrinário de normas exigidas por um ou mais deuses como modo de vida aceitável para seu povo, capaz até mesmo de alterar o "caráter naturalmente espontâneo 
da vida laica no mundo" (WEBER, 2004, p. 116). Assim sendo, quando Weber afirmou que o mundo moderno se desencantava, não o fez no sentido de que este perdia seus vínculos religiosos; mas sim de que se desencantava uma vez que perdia sua magia. Logo, o desencantamento do mundo, em seu sentido estrito, é a passagem da magia para a religião, processo que, segundo Weber, teve sua máxima expressão no protestantismo de linha puritana:

Somente o protestantismo ascético efetivamente aniquilou a magia (...). Para a religiosidade popular asiática de qualquer tipo, ao contrário, o mundo permaneceu um grande jardim encantado: a veneração ou a coação dos "espíritos", a busca de salvação ritualista, idolátrica, sacramental, continuaram sendo o caminho para se orientar e se garantir na prática (WEBER apud PIERUCCI, 2005, p. 112).

Para os fins deste artigo, contudo, concentraremos nossas atenções nessa forma mais primitiva de relação com o sagrado. A magia é fortemente apegada à tradição, avessa às mudanças, repleta de rituais. Magia é tentativa, é controle, é estratégia para obter salvação. Magia é irracionalidade, mas existe uma lógica por trás de suas práticas. Pierucci esclarece: "os bens que as pessoas procuram obter com a magia preenchem realmente a definição do que sejam fins indiscutivelmente racionais: dinheiro, comida, saúde, longevidade e descendência" (PIERUCCI, 2005, p. 75). Magia é antes de tudo "irracionalidade extracotidiana” (PIERUCCI, 2005, p. 78), uma vez que se encontra ancorada em rituais sucessivos, porém pontuais, momentos de êxtase e invocação de poderes sobrenaturais fora da ordem cotidiana.

Em contraste com a religião, ela não está ativa nas 24 horas do dia. Há momento para a sua corporificação. A magia é extremamente pragmática, funciona através de liturgias e ritualísticas, na tentativa de manipular os deuses. Ela é o deus a serviço do homem e justamente por isso tem finalidades definidas: atingir objetivos estritamente mundanos. Pierucci deixa explícito: "os interesses mágicos são totalmente deste mundo (...). Nada aí é metafísico, nada é para o outro mundo, nada é para o lado de lá” (PIERUCCI, 2005, p. 80). Ainda, a magia desconhece a ética, pois 
lhe falta "a clareza da distinção entre uma regra técnica e uma regra normativa, além de faltar-lhe, de quebra, a diferenciação entre a utilidade e o dever" (PIERUCCI, 2005, p. 74). Não se preocupa, portanto, com uma prática racionalizada de uma vida em consonância e coerência com princípios éticos divinos. O foco da magia, por conseguinte, está nos bens objetivados, bens estes que seriam até capazes de gerar felicidade.

A essa altura, poderíamos concluir, de forma apressada, que o reencantamento do mundo possa significar o simples retorno à magia. Como uma espécie de "ressacralização", o que simularia um "eclipse" na secularização que assistimos. Essa associação, embora fácil de ser feita, nos parece equivocada. A suposição de que a nossa sociedade estaria fazendo um mero retorno a um estágio de desenvolvimento pré-moderno, desconsiderando todo o percurso histórico e cultural no qual estamos, conscientemente ou não, imersos e enraizados, e do qual seria impossível desvencilhar-nos, mostra-se tendenciosa e, até mesmo, bastante ingênua. Reencantamento do mundo não é isso. Como adverte Pierucci (2005, p. 221),

o locus da existência humana em que se esgueira uma possibilidade efetiva de encantar novamente o mundo não é a esfera religiosa, mas uma outra esfera cultural, ao mesmo tempo não-religiosa e não-racional: a esfera erótica, onde reina, segundo Weber, a 'potência mais irracional da vida' - o amor sexual.

Ainda assim, e trataremos disso mais adiante, é plenamente possível percebermos muitas similaridades entre a magia e os diversos comportamentos pós-modernos, sobretudo nas práticas de consumo. Magia não no sentido estritamente religioso, mas num sentido muito mais amplo, que a aproxima, inclusive, desta esfera erótica mencionada por Pierucci.

\section{0 retorno dos sentidos}

Tentemos, agora, olhar para o panorama contemporâneo por outro prisma. É fato que as propostas da modernidade se mostraram insuficientes 
para atender plenamente aos anseios e demandas do ser humano por afeto, intimidade, sentido, conhecimento, transcendência. Se, por um lado os valores religiosos baseados na fé, bem como as crendices, superstições, experiências místicas e emocionais perderam lugar para a razão; por outro lado, deixaram uma lacuna a ser preenchida no cotidiano social que o racionalismo ético, técnico e científico simplesmente não teve a competência para preencher. Ao refletir sobre os efervescentes anos do final da década de 1960 e início da de 1970, Colin Campbell fala de "uma acentuada alienação da cultura da racionalidade e um decidido antipuritanismo" (CAMPBELL, 2001, p. 12) entre os jovens. Alguns analistas apontam para certa saudade e para um movimento de retorno que muitas pessoas, na atualidade, começam a empreender em direção ao primitivismo, ao irracional, ao imaterial, em busca de felicidade. Mencionamos aqui apenas dois, ambos franceses: o sociólogo Michel Maffesoli e o filósofo Daniel Bougnoux.

Mesmo contando com aparatos metodológicos, linguagem e pontos de partida bem diferentes, os dois autores têm em comum o fato de contrastarem modernidade e pós-modernidade em análises que se tocam em muitos pontos. Ambos expressam boas doses de otimismo ao teorizarem um retorno aos contatos mais primitivos, anteriormente abandonados pela modernidade.

Analisando as mudanças que afetam, na contemporaneidade, as relações humanas e a emergência de novas formas de agrupamento social, Maffesoli conclui que o modelo proposto pela modernidade encontra-se saturado. Em seu lugar, novas relações têm se estabelecido no que ele chama de "socialidade" (MAFFESOLI, 1998, p. 79). Em suas palavras: "Após um período em que prevaleceu o distanciamento, um 'período ótico’, que se poderia chamar, com referência à sua etimologia, de período teórico (theorein: ver), se estaria entrando num período 'táctil', no qual apenas a proxemia importa” (MAFFESOLI, 1998, p. 46). Para o autor, estamos, pois, em processo de mudança. Não é algo racionalmente pensado ou planejado. Passa por outros caminhos mais espontâneos, ligados a elementos que estavam meio adormecidos como a emoção, o afeto e o sentimento. Assim, à "estrutura mecânica” composta por "indivíduos" 
de funções bem definidas que se reúnem em "grupos contratuais”, todas estas características bem próprias da modernidade, Maffesoli contrapõe esquematicamente uma "estrutura complexa e orgânica", que se vem desenhando na pós-modernidade, na qual "pessoas" estão a desempenhar papéis e se congregam em "tribos afetuais” (MAFFESOLI, 1998, p. 9).

Daniel Bougnoux parece trilhar raciocínio semelhante, tendo como base, porém, os pressupostos da semiótica de Peirce. Debruçando-se sobre as três categorias nas quais estão divididos os signos, isto é, os índices, ícones e símbolos, Bougnoux (1994) estabelece uma forte ligação entre o signo e o processo de desenvolvimento cultural do indivíduo e do grupo social. Para ele, "o acesso ao simbólico reprime o índice: suprime os sentidos (as sensações) em proveito do sentido (a significação). O homem desenraiza-se da natureza para dominá-la ou corrigi-la" (BOUGNOUX, 1994, p. 67). O que o autor sugere é que, no processo de aprendizagem pelo qual o indivíduo passa ao longo da vida, e de forma mais ampla, no desenvolvimento civilizatório das sociedades, comunicação e interação vão se tornando cada vez mais frias e impessoais, artificializam-se através da utilização de códigos, cada vez mais abstratos (os símbolos).

Os primeiros contatos com o mundo, pelo instinto e pela emoção isto é, os índices -, que são, por natureza, cheios de vitalidade, vão sendo progressivamente abafados ou disciplinados no processo de aculturação. Podemos dizer que a modernidade corresponderia, pois, para Bougnoux, a esta atmosfera fria e racional, pretenso domínio do intelecto em detrimento de todo o resto. Nesse ponto, o autor dá um passo à frente e fornece uma concreta chave de interpretação para a pós-modernidade.

É o que Bougnoux chama de "regressão estética" (BOUGNOUX, 1994, p. 67). Os indivíduos têm dado sinais claros dessa "saudade" do contato indicial. As atuais formas de agrupamento social, de religiosidade, de vínculo entre os indivíduos e destes com as instituições, as práticas de consumo e as novas mídias estão aí para comprovar isto. O mesmo se constata na revalorização do sensorial e da emoção. Basta olharmos com atenção para o cinema, para a publicidade e para as estratégias do marketing, cada vez mais direcionadas para o envolvimento afetivo do 
consumidor, humanizando marcas e promovendo a exaltação da imagem, da aparência, da estética em todos os campos.

Com efeito, tais abordagens parecem, em algum nível, alinhar-se com a noção de reencantamento do mundo. Mas será mesmo que poderíamos falar de reencantamento ligado a esta revalorização da emoção, do calor, dos contatos mais primitivos, do toque e do afeto nas relações humanas? Voltaremos à temática da magia a fim de esboçar algumas correlações possíveis, mas, antes disso, olhemos para um traço que se mostra determinante para compreendermos a lógica que subjaz à pós-modernidade: o consumo.

\section{Consumo, estética e felicidade}

Reafirmamos que o processo de retorno do encantamento em nossos dias não está no mero recrudescimento da religião em suas formas mais primitivas, embora, especialmente no cenário brasileiro, possamos até falar de uma efervescência místico-religiosa - esta que, corporificada nos surtos religiosos contemporâneos, sugeririam uma "volta”, um "retorno" da religião, o que foi denominado por Kepel (1991) de "Revanche de Deus". Mas insistimos: não é esta a abordagem que aqui propomos.

O reencantamento do mundo está associado, isto sim, às práticas, um tanto quanto utilitaristas, irracionais, emocionais, sensoriais, comunitárias e ritualistas, que emergem do cotidiano. Ao que parece, é precisamente dessas práticas que temos buscado extrair significado, identidade, transcendência, completude, afeto, pertença e, em resumo, felicidade. E o fato que salta aos olhos, numa observação atenta da atualidade, é que o lugar, por excelência, dessas práticas é o consumo. Déborah Pereira da Silva, doutora em Comunicação e Semiótica e mestre em Ciências da Religião pela PUC de São Paulo, coloca a questão da seguinte maneira:

Adotamos a ideia de que, por meio da publicidade desenvolvida pelos investimentos capitalistas, se ressignifiquem sentidos para a vida por meio do consumo. Dessa forma, produtos e serviços puderam se tornar fragmentos do projeto de felicidade e, lentamente, ingressaram na esfera de 
significação da vida humana, que durante séculos havia se sustentado quase que exclusivamente no universo religioso (PEREIRA, 2008, p. 93).

Projeto de felicidade. Nossa busca por felicidade estaria passando hoje, obrigatoriamente, pelo âmbito do consumo. Isto é o que leva Zygmunt Bauman a nomear a nossa sociedade como uma "sociedade de consumidores", na qual "os vínculos humanos tendem a ser conduzidos e mediados pelos mercados de bens de consumo" (BAUMAN, 2008, p. 107 e 108), uma sociedade "do excesso e da extravagância" (BAUMAN, 2008, p. 112). Ao contrário do tom de entusiasmo que se pode sentir em Michel Maffesoli, para o qual estaríamos imersos numa "aura estética” (MAFFESOLI, 1998, p. 20), ela mesma fator de agregação social, onipresente nas ambiências pós-modernas.

Bauman (2008), numa perspectiva outra, critica em muitos aspectos, a qualidade e os resultados desse processo de mudança e ressignificação do consumo. É o que se pode ver, por exemplo, em sua análise da cultura consumista, na qual, inclusive, cita Maffesoli (BAUMAN, 2008, p. 107-148).

O apelo insistente, e até pedagógico, da publicidade para que estejamos e permaneçamos sempre à frente da tendência de estilo só é possível de ser efetivado, para Bauman, com base no medo que sentimos de ficar para trás, em troca de alguns sacrifícios e na adoção de um estilo de vida que exige uma boa e constante dose de esforço. Como na sociedade de consumidores, o sentimento de pertença só é obtido "por meio da própria identificação metonímica do aspirante com a tendência" (BAUMAN, 2008, p. 108), precisamos, por isso, urgentemente portar os "emblemas de pertença" e passamos, então, a viver em estado de alerta constante a fim de saber quais são os produtos e comportamentos que, neste exato momento, estão em alta, aqueles que são tendência e, obviamente, os que estão deixando de circular para serem substituídos por outros (BAUMAN, 2008, p. 108).

Além da publicidade, do próprio mercado e dos consumidores, podemos perceber que as figuras emblemáticas, as pessoas que as escolhem como tais, os emblemas de pertença e os grupos aos quais estes se 
remetem, também são incluídos como partes constituintes nesse processo consumista. Bauman ainda põe em relevo uma espécie de ciclo do consumo, bastante elucidativo, que "começa com a aquisição de emblemas, passa pelo anúncio público de sua posse e só é considerado completo quando a posse se torna de conhecimento público" (BAUMAN, 2008, p. 108). Pensando especialmente nesse ato de publicar a posse a que ele se refere, vale destacar o quanto a internet e, em especial, as redes sociais cumprem um papel central. Seria esse o motivo de muitos de nós não conseguirmos nos desconectar nunca? O medo, muito provavelmente, figura como uma das forças que motivam as práticas de consumo atuais:

A referência de "estar à frente" sugere uma preocupação genuína de menosprezar o momento em que os atuais emblemas de "pertença" saem de circulação, sendo substituídos por novos, e em que seus portadores desatentos se arriscam a ficar à margem - o que no caso do pleito, mediado pelo mercado, para se tornar membro, traduz-se como o sentimento de ser rejeitado, excluído e abandonado, e em última instância se reflete na dor aguda da inadequação pessoal (BAUMAN, 2008, p. 109).

Se é através dos códigos estéticos, que portamos e publicamos, que podemos afirmar quem somos e onde nos posicionamos numa sociedade que renova continuamente (e cada vez mais depressa) suas marcas de pertença, é fácil chegar à seguinte conclusão lógica: estar desatentamente satisfeito é extremamente desaconselhável. Para o "Homo consumens" (BAUMAN, 2008, p. 127), há muito risco em portar as coisas por tempo demais. Precisamos ser insaciáveis. Não podemos parar de experimentar as sensações que o ato de consumir, mesmo que por um breve momento, nos passa. Devemos sentir, ainda que ilusoriamente, que temos valor, que somos queridos, que representamos algo para alguém. Identidade, no final das contas, é o que está em jogo. Na pós-modernidade, portanto, nossa identidade vai se constituindo a partir do outro, um outro que, para Bauman, especialmente nos espaços virtuais, "é reduzido a seu núcleo duro de instrumento de autoconfirmação um tanto manipulável" (BAUMAN, 2008, p. 148). A renovação constante da aquisição de 
produtos e a devida publicação da posse seriam responsáveis nesse ciclo do consumo por trazer segurança ao indivíduo, este que, na contemporaneidade, se distingue como medida e como fim.

Sentir satisfação, sentir pertença, sentir irracional, pois mesmo que de forma ilusória, sentir-se um, um com o Outro. Por isso, falar de um "paradigma estético" para definir a pós-modernidade (MAFFESOLI, 1998, p. 15) ou de um Homo eroticus, nome do mais recente trabalho de Michel Maffesoli, no qual o autor retoma e reforça os 30 anos de sua obra. Para ele, este é o clima da nossa época: ligações frágeis, "mas que, no seu momento, são objeto de forte envolvimento emocional" (MAFFESOLI, 1998, p. 107). Se ousarmos tomar a magia tal qual descrita por Weber, no sentido religioso ampliado deste religare adotado por Maffesoli (MAFFESOLI, 1998, p. 109), conseguiremos ver alguns paralelos bem sugestivos. É precisamente nessa instância da religação com o outro, na qual religião e erotismo, de certa forma, se fundem, que poderíamos falar de um reencantamento do mundo através do consumo.

\section{0 reencantamento via consumo}

Fica claro, até aqui, o quanto os hábitos e bens de consumo têm adquirido novos significados na atualidade, significados estes ligados ao sentimento, às sensações, às emoções e ao afeto. É nítida também a relação direta, metonímica, com a maneira pela qual tentamos construir nossa identidade, uma vez que "os bens de consumo dificilmente são neutros em relação à identidade; tendem a vir com o selo identidade incluída" (BAUMAN, 2008, p. 143). Chegamos, assim, finalmente, ao que nos parece ser uma importante chave para a compreensão da pós-modernidade: vivenciamos um reencantamento do mundo via consumo.

Em primeiro lugar, é preciso lembrar que, através de intermináveis rituais, a busca empreendida pela magia era, em última análise, para obter felicidade. Ela não se propunha a normatizar a totalidade da vida cotidiana, com regras morais que dessem sentido à existência repercutindo na eternidade. Antes, encontrava nos momentos pontuais 
sua realização, objetivando ganhos aqui, agora, neste mundo. Se, como argumentam Maffesoli e Bougnoux, presenciamos a revalorização de impulsos primitivos que a modernidade tentou abafar, é possível traçar pontos de contato entre as referidas práticas de consumo, observadas na pós-modernidade, e os princípios que orientavam as práticas mágicas de outrora. Para alicerçar este nível final de nossa argumentação, utilizaremos mais uma imagem bastante forte e, para muitos, excessivamente pessimista, fornecida por Zygmunt Bauman: "A identidade é uma pena perpétua de trabalhos forçados” (BAUMAN, 2008, p. 142).

Na lógica que rege as atuais práticas de consumo, não dá para escapar: precisamos renovar a todo instante nossas garantias de segurança. A ideia é mesmo de necessidade, indispensabilidade. Num contexto no qual hábitos e bens de consumo, na relação em sociedade, definem quem somos, simplesmente não podemos parar de consumir, adquirindo e tornando pública a posse dos bens, numa espécie de pena perpétua, como descreve Bauman. Numa época em que se fala tanto de liberdade, estamos de certa maneira aprisionados, obrigados ou, para usar um termo mais pesado, condenados a cumprir uma série de trabalhos forçados.

Maffesoli se empenha em tentar descrever essa maneira pós-moderna de relacionarmo-nos uns com os outros, via consumo, usando a metáfora da tribo, que por si mesma já evoca muitas palavras que remetem a um primitivismo: ritual, união, agregação, luta, misticismo, território. Para o autor, temos a necessidade de defender um território simbólico que nos une, que nos desperta memórias coletivas, sentimentos que fazem com que nos reconheçamos como membros da tribo. Isto não ocorre através de manifestos políticos. É nas práticas ritualísticas do cotidiano que espontaneamente mostramos quem somos e de onde viemos. Se na pós-modernidade, o sentido foi mesmo substituído pelo sentimento, tendemos a colocar toda a energia na estética. Estética como laço social. Muito frágil?

De fato, para que isso funcione, muita energia precisa ser gasta todos os dias, através de rituais repetidos que reafirmem o sentimento de grupo. A preocupação com a construção (ou manutenção) da identidade 
não se resume ao vestuário. É preciso comprar, ouvir, estar constantemente atualizado na cena, frequentar os mesmos lugares, circular pelos mesmos espaços. Afinal, novos padrões de consumo são adquiridos. Mas custa caro, e não só financeiramente. Existe um gasto (maior ou menor) de energia, emoção e tempo envolvido no processo. São esses rituais - ou "trabalhos forçados" na linguagem de Bauman - que em sua repetição nos dão a impressão de segurança (MAFFESOLI, 1998, p. 25).

Assim, a partir do cotidiano consumista, e obviamente com o forte estímulo dos "vendedores de bens de consumo" (BAUMAN, 2008, p. 142), vemos renascer com força algumas características próprias daquelas práticas mágicas descritas por Weber. Essa obrigatória repetição - que se observa nos rituais de consumo pós-modernos - se verifica também na lógica que embala a magia. E não apenas isso, mas o fator motivador dos rituais parece bastante semelhante. À luz da história das religiões e da filosofia, o teólogo sistemático Louis Berkhof afirma a universalidade do sentimento de culpa presente, em todas as culturas, no ser humano responsável por nos conduzir às ações religiosas e aos sacrifícios: "Há um sentimento generalizado de que os deuses estão ofendidos e devem ser aplacados de algum modo" (BERKHOF, 1990, p. 235). Assim, como nas ações religiosas do mundo outrora encantado e descrito por Weber, estaríamos hoje impondo-nos o dever de realizar, incansavelmente, rituais intermináveis para "sermos salvos". Salvação, vale lembrar, tendo em vista apenas itens ligados a este mundo: dinheiro, comida, saúde, realização, amor. Pierucci realça ainda um caráter comercial de troca presente na magia: "No gesto de coagir os espíritos com uma fórmula mágica, e não de lhes fazer um pedido, está obtida a certeza de obter deles uma intervenção que vá no sentido desejado pelo cliente e ordenado carismaticamente pelo feiticeiro" (PIERUCCI, 2005, p. 75).

Fica evidente, portanto, o aspecto utilitarista da magia, assim como, em nossas vivências pós-modernas, o outro vai sendo reduzido a um instrumento para nossa autoafirmação. Destaca-se ainda o fato de que, ao falar de magia estamos falando de momentos pontuais de relação com o sagrado e não de uma vida inteiramente dedicada à observância 
de regras. No consumismo pós-moderno, como descreve Bauman, o momento precisa ser renovado a cada instante, pois estar satisfeito não interessa mais. Tampouco o engajamento em causas duradouras. A ética puritana que ajudou a promover o espírito do capitalismo estaria dando a vez a uma "ética romântica", que opera e viabiliza o "espírito do consumismo” (CAMPBELL, 2001, p. 15). A ética tende a se dissolver, embora o discurso sobre ela esteja mais fértil do que nunca. Luiz Felipe Pondé chega mesmo a comentar sobre uma "fé na ética", segundo ele, muito comum hoje em dia, e argumenta: "quando não se sabe o que falar, fala-se de ética” (PONDÉ, 2012, p. 144).

Logo, a ênfase consumista está nos ganhos, não necessariamente na conduta de vida. Assim como a magia tem seu domínio num campo essencialmente politeísta, para Maffesoli, a religião única proclamada no contexto moderno está dando lugar a "um politeísmo de contornos sempre indefinidos” (MAFFESOLI, 2001, p. 110). Para o autor, este politeísmo não significa a existência real de muitos deuses, mas de uma nuvem de elementos, grande parte deles estéticos, cuja função espera-se que seja a de religar as pessoas umas às outras. É o que parece apontar também Pierucci, ao rememorar a expressão weberiana "politeísmo de valores” com seus “deuses desencantados” (PIERUCCI, 2005, p. 137, 139).

Por tudo o que foi exposto, acreditamos estar vivenciando um reencantamento do mundo através do consumo. Uma aproximação um tanto quanto paradoxal. Entretanto, perceber a relação intrincada entre a aparente alegria evocada pelo retorno do encantamento e o doloroso aprisionamento contido na pena perpétua dos rituais de consumo desafia o senso comum. Um olhar mais atento permite-nos questionar, por um lado, se o reencantamento do mundo é assim tão feliz quanto sua semântica (e alguns entusiastas) sugere, ao mesmo tempo que nos leva a refletir se análises mais críticas da sociedade de consumo, como as de Bauman, não poderiam, efetivamente, nos ajudar a encontrar melhores caminhos pelos quais trilhar na relação com o outro. 


\section{Referências}

BAUMAN, Z. Vida para consumo: a transformação de pessoas em mercadoria. Rio de Janeiro: Jorge Zahar, 2008.

BERKHOF, L. Teologia Sistemática. Campinas: Luz Para o Caminho, 1990.

BOUGNOUX, D. Índices, Ícones, Símbolos. In: BOUGNOUX, D. Introdução às Ciências da Informação e da Comunicação. Petrópolis: Vozes, 1994.

BRUBAKER, W. Racionalização. In: OUTHWAITE, W.; BOTTOMORE, T. (Eds.). Dicionário do Pensamento Social do Século XX. Trad. Eduardo Francisco Alves e Álvaro Cabral. Rio de Janeiro: Zahar, 1996.

CAMPBELL, C. A ética romântica e o espírito do consumismo moderno. Rio de Janeiro: Rocco, 2001.

GUINNESS, OS. O chamado. São Paulo: Cultura Cristã, 2001.

KEPEL, G. A revanche de Deus. São Paulo: Siciliano, 1991.

MAFFESOLI, M. O tempo das tribos: o declínio do individualismo nas sociedades de massa. 2. ed. Rio de Janeiro: Forense Universitária, 1998.

MAFFESOLI, M. Sobre o nomadismo: vagabundagens pós-modernas. Rio de Janeiro: Record, 2001.

PEREIRA, D. A comunicação publicitária como reencantamento: a relação entre publicidade e religião no Brasil e na América Latina. São Paulo: PUC-SP, 2008. Tese (doutorado em Comunicação e Semiótica) - Pontifícia Universidade Católica de São Paulo, São Paulo, 2008.

PIERUCCI, A. F. O desencantamento do mundo: todos os passos do conceito em Max Weber. São Paulo: Ed. 34, 2005.

PONDÉ, L. F. Guia politicamente incorreto da filosofia. São Paulo: Leya, 2012.

WEBER, M. A ética protestante e o espírito do capitalismo. São Paulo: Martin Claret, 2004.

WEBER, M. Ensaios de sociologia. Org. e introd. H. G. Gerth e C. Wright Mills. Rio de Janeiro: Zahar, 1963. 


\section{Sobre os autores}

Karla Patriota Bronsztein - Doutora em Sociologia pela Universidade Federal de Pernambuco (UFPE). Professora adjunta 4 do curso de Publicidade e Propaganda da Universidade Federal de Pernambuco e do Programa de Pós-graduação em Comunicação (PPGCOM).

Bruno Anselmo da Silva - Mestrando em Comunicação pelo Programa de Pós-graduação em Comunicação da Universidade Federal de Pernambuco (UFPE).

Data de submissão: 13/08/2015

Data de aceite: 15/03/2016 